Savino M. Di Stasi - Antonella Giannantoni

Pierluigi Navarra · Renato Massoud

Daniela Zavaglia $\cdot$ Pierfrancesco Bertucci

Giuseppe Vespasiani · Robert L. Stephen

\title{
The stability of lidocaine and epinephrine solutions exposed to electric current and comparative administration rates of the two drugs into pig bladder wall
}

Received: 14 August 2002/ Accepted: 20 March 2003/Published online: 8 May 2003

(C) Springer-Verlag 2003

\begin{abstract}
Intravesical electromotive administration of local anesthetics is clinically successful but electrochemistry, cost and effectiveness limit the choice of drugs to diluted lidocaine $\mathrm{HCl} 4 \%$ mixed with epinephrine. These studies address the stability of lidocaine and epinephrine both over time and when exposed to electric current, i.e. transport rates with passive diffusion and electromotive administration. The drug mixture used was $50 \mathrm{ml}$ lidocaine $4 \%, 50 \mathrm{ml} \mathrm{H}_{2} \mathrm{O}$ and $1 \mathrm{ml}$ epinephrine $1 / 1000$. For stability, the solution was placed either in bowls for 7 days or in a two chamber cell with the donor compartment (drugs) separated from the receptor compartment $(\mathrm{NaCl}$ solution) by a viable pig bladder wall. This was subjected to $30 \mathrm{~mA}$ for $45 \mathrm{~min}$. Stability was measured with mass spectrometry. The cell was also used to determine transport rates with passive diffusion and currents of $20 \mathrm{~mA}$ and $30 \mathrm{~mA}$, over 20,30 and $45 \mathrm{~min}$. Drug measurements in both compartments and bladder were made with HPLC. Lidocaine remained stable throughout the 7 days, epinephrine on day 1 only and both drugs were stable with $30 \mathrm{~mA}$ for $45 \mathrm{~min}$. Comparing $20 \mathrm{~mA}$ and $30 \mathrm{~mA}$ with passive diffusion, there were significant differences in $6 / 6$ donor compartment
\end{abstract}

S. M. Di Stasi $(\bowtie) \cdot$ D. Zavaglia $\cdot$ G. Vespasiani Department of Urology, Tor Vergata University, Via Torrice no. 4, 00189 Rome, Italy

E-mail: sdistas@tin.it

Tel.: + 39-6-30311655

Fax: $+39-6-23188353$

A. Giannantoni

Department of Urology, University of Perugia, Perugia, Italy

P. Navarra

Institute of Pharmacology, Catholic University,

Rome, Italy

R. Massoud · P. Bertucci

Department of Clinical Biochemistry,

Tor Vergata University, Rome, Italy

R. L. Stephen

Physion Laboratories, Medolla, Italy lidocaine levels, $4 / 6$ receptor compartment levels and $6 / 6$ bladder tissue levels and also in 6/6 epinephrine donor levels and $6 / 6$ tissue levels. The combination lidocaine and epinephrine remains stable for 1 day and when exposed to $30 \mathrm{~mA}$ for $45 \mathrm{~min}$. Electric current accelerates the transport of lidocaine and epinephrine.

Keywords Lidocaine Epinephrine Electric current $\cdot$ Stability $\cdot$ Transport rates

\section{Introduction}

Lidocaine, introduced in 1948, is probably the most widely used local anesthetic today, with applications ranging from infiltration anesthesia to field blocks, epidural anesthesia, spinal anesthesia and intravenous regional anesthesia [14]. Almost all local anesthetic agents are practically insoluble in water but freely soluble in ethanol and many oils (lipids). Therefore, injectable lidocaine is supplied as the water-soluble, ionized hydrochloride salt $\left(\mathrm{Ld}^{+}, \mathrm{Cl}^{-}\right)$with a $\mathrm{pH}$ of 5-7. It has proved to be effective and safe for more than 50 years. However, when instilled intravesically, this formulation provides only superficial anesthesia $[11,16]$ because, with a $\mathrm{pKa}$ of 7.9 units, lidocaine is about $98 \%$ ionized at $\mathrm{pH} \sim 6.0$ and the permeability of urothelium to ionized polar molecules is very low [7]. Henry et al. buffered lidocaine $\mathrm{HCl}$ to $\mathrm{pH} \sim 8.0$ units with $\mathrm{NaHCO}_{3}$ and achieved good penetration of the bladder wall with some $60 \%$ of the lidocaine present as the lipid-soluble, non-ionized base [6].

Another approach that assists penetration of the urothelial barrier is electromotive administration. When electric current is applied to an aqueous solution, the delivery of solutes into underlying tissues is accelerated by at least three electrokinetic phenomena [1]. For ionized molecules the most important of these is iontophoresis, defined as: the active transport of ionized molecules by the application of an electric current of appropriate polarity through a solution containing the ions 
to be delivered. The normally random motion of the molecules is uniformly directed towards underlying tissues, their momentum is increased and drug administration rates can be calculated using equations derived from Faraday's law [10]. Numerous reports over decades attest to the efficacy of iontophoretic local anesthesia applied to the skin and tympanic membrane [1], but only during the last 8 years has this approach been employed to provide adequate bladder anesthesia for transurethral resection of bladder tumor $[4,8,9]$ and cystodistension $[5,13]$. Because the bladder is both the target organ and the drug receptacle, there are certain unique constraints in addition to those normally associated with electromotive administration.

A generously perforated catheter containing the active electrode must be approximately centralized within the bladder to avoid biased delivery to the nearest section of bladder wall. For the same reason the bladder must be sufficiently distended to smooth out the rugal folds, with a $100 \mathrm{ml}$ volume minimum [9] which provides a surface area $\geq 106 \mathrm{~cm}^{2}$, far larger than the usual area of skin anesthesia $\left(8-10 \mathrm{~cm}^{2}\right)$. Therefore, electric current must be increased from the usual 2-4 mA to $15-30 \mathrm{~mA}$ in order to carry out treatment within a reasonable time frame of 15-30 min. As with all iontophoretic treatments, competing ions are to be avoided if at all possible. This causes difficulties because the great majority of injectable local anesthetics contain appreciable quantities of strongly competitive $\mathrm{NaCl}$ ions [4]. The exceptions are spinal anesthetic solutions, $100 \mathrm{ml}$ of which are prohibitively expensive, and the inexpensive lidocaine $\mathrm{HCl} 4 \%$ in $50 \mathrm{ml}$ vials, which is diluted down with sterile water [8]. Inflowing urine causes increasing ionic competition for electric current, therefore lidocaine $2 \%$, rather than the otherwise effective $0.5 \%$, is usually selected. Finally, the effect of lidocaine alone proved to be too short acting (15-20 min), so epinephrine at an arbitrary $1 / 100,000$ was added and the duration of anesthesia lengthened to a satisfactory 50-60 $\min [4,9]$. In spite of clinical success, several aspects of the intravesical electromotive administration of lidocaine and epinephrine when so mixed have not been clarified: (1) the stability of the two drugs both for hours or days following admixture as well as when electric current is applied; (2) comparative transport rates of lidocaine and epinephrine with passive diffusion and electromotive administration. This present laboratory study addresses these issues.

\section{Materials and methods}

Viable bladder sections

At a nearby abbattoir, pigs weighing $150 \pm 18 \mathrm{~kg}$ were killed using the standard technique of electronarcosis and incision of the great veins and arteries of the neck, and 15-20 min later the bladders were rapidly excised, placed in a cell culture medium $(1 \times \mathrm{DMEM}$, HyClone Europe, Cramlington, UK) at $4^{\circ} \mathrm{C}$ and transported to the laboratory.
Drug solution

The drug solution in all experiments was the same as that used in clinical application: $50 \mathrm{ml}$ lidocaine $\mathrm{HCl} \mathrm{4 \%}$ (NaCl-free), $1 \mathrm{ml}$ epinephrine $\mathrm{HCl} 1 / 1,000(1 \mathrm{mg} / \mathrm{ml}), 50 \mathrm{ml} \mathrm{H}_{2} \mathrm{O}$ which resolves to lidocaine $1.98 \%$ with epinephrine $1 / 101,000(2 \%$ and $1 / 100,000$ for all practical purposes).

\section{Bench equipment}

A battery-powered generator (Physion, Medolla, Italy) providing a programmable output of 1-30 mA (pulse) over programmable times of 1-45 min was used as the current source. Two silver plated spiral wires functioned as electrodes and were placed in a twochamber cell which separated the drug solution (donor compartment) from $100 \mathrm{ml} \mathrm{NaCl} 0.9 \%$ (receptor compartment) with a section of viable bladder wall (2.3-2.8 g) sealed without tension in the inter-compartmental window and exposing urothelium (area $1.8 \mathrm{~cm}^{2}$ ) to the drug solution [2].

\section{Drug stability studies}

To measure the duration of drug stabilities, the lidocaine and epinephrine mixture was placed in open steel bowls and stored for up to 7 days: (1) at room temperature with normal lighting, (2) at room temperature in the dark, and $(3)$ at $4^{\circ} \mathrm{C}$ in the dark. On day 1 , samples were taken at 2, 3, 4, 5, 6 and $8 \mathrm{~h}$. On days $2-7$, one sample was taken on each day. For electromotive administration, the drugs and $\mathrm{NaCl}$ solutions were placed in their respective compartments with the section of pig's bladder sealed in the window. Samples were taken from the donor compartment immediately prior to the application of electric current and following $30 \mathrm{~mA}$ for $45 \mathrm{~min}$ (total charge $=1,350 \mathrm{~mA}$ min).

Measurements were performed with a bench-top triple-quadrupole mass spectrometer (Perkin-Elmer Sciex, Concord, Ontario, Canada) in the ion spray mode with an ionization probe operated at a sprayer voltage of 5,000 V. Data were acquired and processed using analyst software and instrument optimization was performed automatically using the autotune function included in the software. All data were acquired in the positive ion mode. Mass spectra were collected in continuous flow mode by connecting the built-in infusion pump directly to the ionspray probe and the solutions were infused at $10 \mu \mathrm{l} / \mathrm{min}$. Lidocaine was dissolved in an aqueous solution of $50 \%$ methanol and $0.025 \%$ formic acid. Epinephrine was dissolved in an aqueous solution of $50 \%$ acetonitrile, $0.025 \%$ formic acid and $5 \mathrm{mM}$ ammonium acetate.

\section{Transport rates of lidocaine and epinephrine}

With drug and $\mathrm{NaCl}$ solutions in their respective compartments and bladder wall in the window, passive diffusion was carried out for $2 \times 4$ samples taken from each compartment at 20, 30 and $45 \mathrm{~min}$ $(n=24)$. Electromotive transport (positive polarity): four samples were taken from each compartment following $20 \mathrm{~mA}$ for $20 \mathrm{~min}$, $30 \mathrm{~mA}$ for $20 \mathrm{~min}, 20 \mathrm{~mA}$ for $30 \mathrm{~min}, 30 \mathrm{~mA}$ for $30 \mathrm{~min}, 20 \mathrm{~mA}$ for $45 \mathrm{~min}$, and $30 \mathrm{~mA}$ for $45 \mathrm{~min}(n=24)$.

Tissue samples were weighed and homogenized at room temperature for $1 \mathrm{~min}$ in PBS $(1: 3, \mathrm{w} / \mathrm{v})$ using a Blendor homogenizer (30 ml capacity). The homogenate was then centrifuged at $10,000 \mathrm{~g}$ for $20 \mathrm{~min}$ at $4^{\circ} \mathrm{C}$. The resulting supernatant was divided into two identical volumes for separate processing.

For lidocaine analysis, the sample $(1 \mathrm{ml})$ was mixed with $10 \mu \mathrm{l}$ $(5 \mathrm{mg} / \mathrm{ml})$ of bupivacaine as internal standard and extracted in the solid phase using $1 \mathrm{ml}$ tubes of $\mathrm{RP}-\mathrm{C}_{18}$ preactivated in methanol and $\mathrm{H}_{2} \mathrm{O}$. The tube was washed with three volumes of $\mathrm{H}_{2} \mathrm{O}$ / methanol (3:1), the fraction containing lidocaine was eluted with $0.4 \mathrm{ml}$ of $100 \%$ methanol and $100 \mu \mathrm{l}$ of this sample was injected for HPLC analysis using a RP-C18 column. The chromatographic 
conditions were as follows: mobile phase, $10 \mathrm{mM}$ pH 5.8 sodium phosphate buffer-acetonitrile $(60: 40 \mathrm{v} / \mathrm{v})$; flow-rate, $1 \mathrm{ml} / \mathrm{min}$; detection wavelength $203 \mathrm{~nm}$; time $20 \mathrm{~min}$. For epinephrine analysis, the sample $(1 \mathrm{ml})$ was mixed with $40 \mathrm{ul}$ of dihidroxylbenzylamine $10 \mu \mathrm{g} / \mathrm{ml}$ as internal standard and extracted as described in a catecholamine kit (ESA, Chelmsford, Mass.). Then 50 ul of sample was injected for HPLC analysis using a RP-C18 column Haisil 100 $(150 \times 4.6 \mathrm{~mm})$. The chromatographic conditions were as follows: mobile phase, $90 \%$ buffer $\left(0.05 \mathrm{M} \mathrm{NaH} \mathrm{PO}_{4}, 200 \mathrm{mg} / 1\right.$ sodium dodecyl sulphate adjusted to $\mathrm{pH} 2.8$ ) and $10 \%$ acetonitrile; detection electrochemical, electrode1 potential $+0.25 \mathrm{~V}$, electrode 2 potential $-0.20 \mathrm{~V}$; flow-rate, $1.4 \mathrm{ml} / \mathrm{min}$; time $30 \mathrm{~min}$.

Miscellaneous

The $\mathrm{pH}$ was measured in donor compartments before and after each experiment. The viability and structural features of tissue specimens were assessed with the trypan blue exclusion test and histological examination with $\mathrm{H}$ and E staining [2].

\section{Statistical analysis}

All measurements were performed in duplicate. The data are means \pm SEM of replicates per group. Differences among group means (receptor and donor drug levels in compartments) were subjected to analysis of variance (ANOVA). Direct comparisons (tissue levels) were analyzed by Student's $t$-test.

\section{Results}

\section{Drug stability}

When stored in open bowls, lidocaine remained stable under all conditions from days $1-7$ with $\mathrm{CVs}$ ranging from $2.9-9.3 \%$. Epinephrine remained stable under all conditions during day $1(\mathrm{CV}$ range $2.2-2.9 \%$ ) and for 7 days when stored at $4^{\circ} \mathrm{C}$ in the dark $(\mathrm{CV} 8.1 \%)$ but underwent significant degradation (CV 74-95\%) over 7 days at room temperature. With the application of an electric current, both lidocaine and epinephrine remained stable when exposed to $30 \mathrm{~mA}$ for $45 \mathrm{~min}$ (Figs. 1, 2).

\section{Lidocaine transport rates}

The lidocaine content of the receptor and donor compartments for times 20,30 and $45 \mathrm{~min}$ are shown in Table 1 . With the application of both 20 and $30 \mathrm{~mA}$, the lidocaine levels in all donor compartments were significantly less than the corresponding levels following passive diffusion, whereas receptor compartment levels following $20 \mathrm{~mA}$ for $30 \mathrm{~min}$ and $30 \mathrm{~mA}$ for 20,30 and $45 \mathrm{~min}$ were significantly higher. Taking the corresponding donor/receptor ratios of lidocaine levels, those following electromotive administration exceeded those following passive diffusion by factors averaging 11:1 with $20 \mathrm{~mA}$ and 13:1 with $30 \mathrm{~mA}$ (3:1-28:1). In bladder tissues, all lidocaine levels following all electromotive experiments significantly exceeded the corresponding levels following passive diffusion experiments (Table 1 and Fig. 3). The ratio of tissue lidocaine levels, electromotive administration/passive diffusion, was $6: 1$ $(3: 1-10: 1)$.

\section{Epinephrine transport rates}

Epinephrine was not detected in any of the receptor compartment samples. All donor compartment epinephrine levels following electromotive administration were significantly lower than the corresponding levels following passive diffusion (Table 2, Fig. 4). All tissue levels following electromotive administration significantly exceeded those following passive diffusion and tissue level ratios, electromotive/passive diffusion, averaged 9:1 (4:1-12:1).

\section{Miscellaneous}

Values for $\mathrm{pH}$ averaged 6.0 units before and 6.1-6.4 units after the experiments. There was no trypan blue staining of epithelial, subepithelial or muscle cells, indicating the viability of tissues throughout the experiments. Histological examination of the bladder wall specimens showed a normal structure (Fig. 5A, B).

\section{Discussion}

The availability of local anesthetic solutions at a reasonable price and free of the competitive quantities of $\mathrm{NaCl}$ reduce intravesical electromotive options to $50 \mathrm{ml}$ vials of lidocaine $\mathrm{HCl} \mathrm{4 \%}$ diluted down with sterile water and the addition of epinephrine at an arbitrarily selected $1 / 100,000$ concentration. Although the two drugs are chemically compatible, this particular mixture raised issues that had to be resolved.

Lidocaine is very stable under a wide variety of conditions and problems were neither anticipated nor found. However, the $1 \mathrm{ml}$ ampuls of epinephrine are sealed under nitrogen and contain $\mathrm{Na}$ bisulphite to prevent oxidation. Therefore, when mixed with lidocaine and exposed to the atmosphere with $\mathrm{Na}$ bisulphite diluted 100 -fold, it is simply a question of time before epinephrine is significantly degraded. Another issue is the possible deleterious effect of electric current, although clinical experience has indicated that this is unlikely. Our results resolved two practical issues. First, a solution of lidocaine and epinephrine optimized for iontophoretic administration should be mixed on the day of use and any remainder discarded. Second, both drugs remain stable when subjected to a total charge of $1,350 \mathrm{~mA}$ min, about twice the maximum, 600 $700 \mathrm{~mA}$ min, used for intravesical procedures $[4,8]$.

During passive diffusion, lidocaine did not appear subject to Fick's first law, with quantities in the compartments and in tissues displaying no obvious relationship to time elapsed. A diminishing concentration 
Fig. 1 Mass spectrograph of lidocaine $\mathbf{A}$ before and $\mathbf{B}$ after application of $30 \mathrm{~mA}$ for $45 \mathrm{~min}$
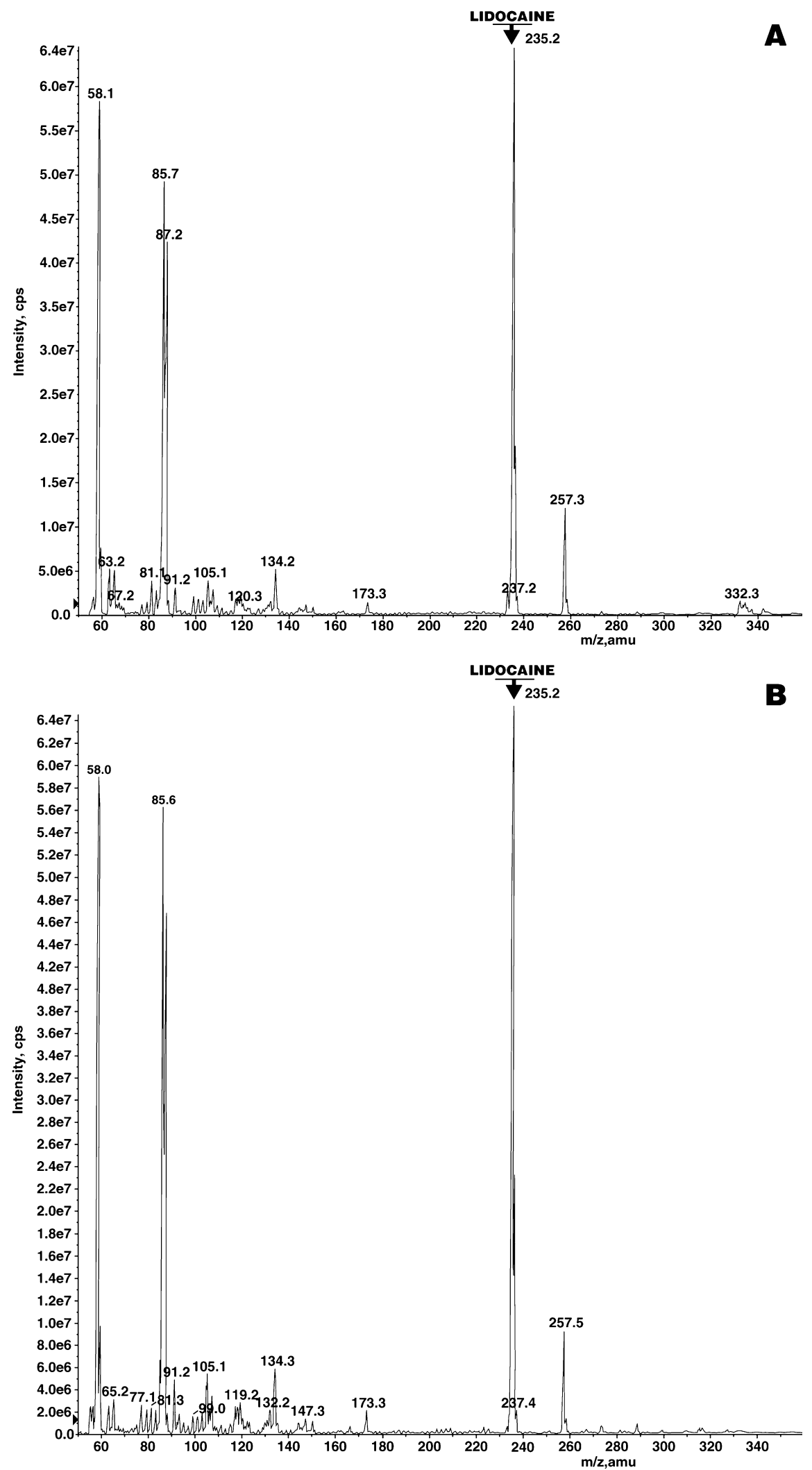

gradient is not the answer (Table 1), so possibly the diffusion coefficient $\left(\mathrm{D}_{\mathrm{L}}\right)$ for lidocaine is not a constant but a variable that declines with time because, following initial uptake, ionized lidocaine stabilizes the urothelial membrane [15] and creates a conformational barrier to further uptake. Conversely, epinephrine levels in tissues showed an almost linear increase with time in spite of its very low concentrations and the technical difficulties 
Fig. 2 Mass spectrograph of epinephrine $\mathbf{A}$ before and $\mathbf{B}$ after application of $30 \mathrm{~mA} \cdot$ for $45 \mathrm{~min}$
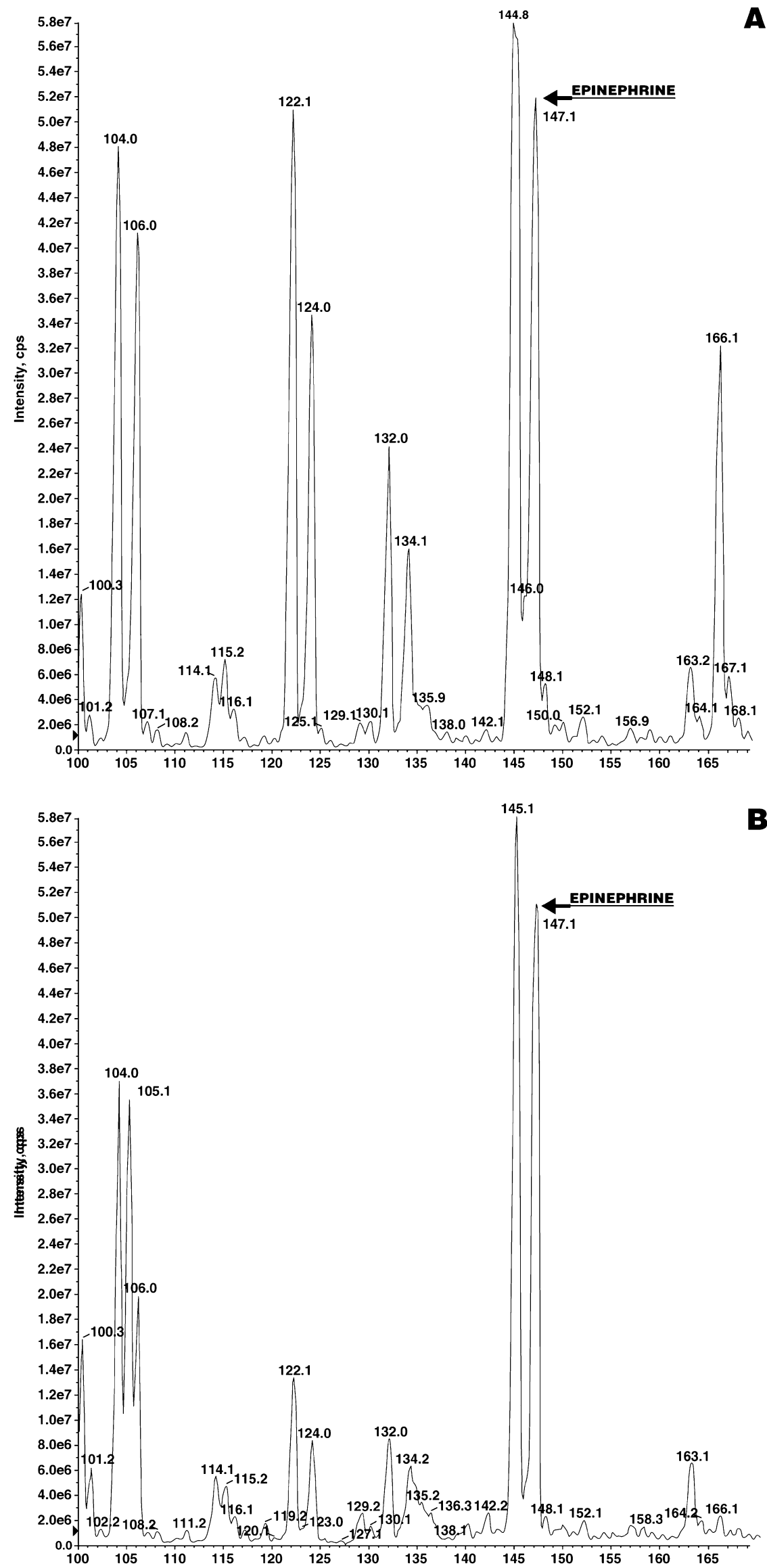
Table 1 Lidocaine levels following passive diffusion and electromotive administration in donor compartment and bladder tissue. Data expressed as means \pm SEM of four replicates per group

\begin{tabular}{|c|c|c|c|c|c|}
\hline Time (min) & \multicolumn{2}{|l|}{ Passive diffusion } & \multicolumn{3}{|c|}{ Electromotive administration } \\
\hline 20 & $19.01 \pm 0.14$ & $0.38 \pm 0.06$ & 30 & $17.50 \pm 0.51^{*}$ & $1.51 \pm 0.29 * *$ \\
\hline 30 & $19.08 \pm 0.10$ & $0.44 \pm 0.11$ & 20 & $15.14 \pm 0.15^{* * *}$ & $3.43 \pm 0.35^{* * *}$ \\
\hline 30 & $19.03 \pm 0.34$ & $0.35 \pm 0.10$ & 30 & $14.50 \pm 0.50 * * *$ & $3.64 \pm 0.42 * * *$ \\
\hline 45 & $18.80 \pm 0.27$ & $0.39 \pm 0.06$ & 20 & $16.56 \pm 0.46^{* *}$ & $2.25 \pm 0.10^{* * *}$ \\
\hline
\end{tabular}

* $P<0.05$ vs corresponding passive diffusion controls

** $P<0.01$ vs corresponding passive diffusion controls

*** $P<0.001$ vs corresponding passive diffusion controls

Table 2 Epinephrine levels following passive diffusion and electromotive administration in donor compartment and bladder tissue. Data expressed as means \pm SEM of four replicates per group

\begin{tabular}{|c|c|c|c|c|c|}
\hline \multirow[t]{2}{*}{ Time (min) } & \multicolumn{2}{|l|}{ Passive diffusion } & \multicolumn{3}{|c|}{ Electromotive administration } \\
\hline & Donor $(\mu \mathrm{g} / \mathrm{ml})$ & Tissue (ng/g wet tissue) & Current (mA) & Donor $(\mu \mathrm{g} / \mathrm{ml})$ & Tissue (ng/g wet tissue) \\
\hline 20 & $9.24 \pm 0.15$ & $17.00 \pm 1.83$ & 20 & $7.39 \pm 0.13 * * *$ & $78.75 \pm 3.97 * * *$ \\
\hline 20 & $8.91 \pm 0.07$ & $21.50 \pm 1.55$ & 30 & $7.39 \pm 0.32 * *$ & $87.25 \pm 4.48^{* * *}$ \\
\hline 30 & $8.37 \pm 0.12$ & $42.00 \pm 5.67$ & 20 & $7.02 \pm 0.20 * *$ & $493.50 \pm 36.25^{* * *}$ \\
\hline 30 & $8.29 \pm 0.24$ & $67.75 \pm 7.65$ & 30 & $6.45 \pm 0.20 * *$ & $814.80 \pm 57.79 * * *$ \\
\hline 45 & $8.17 \pm 0.32$ & $155.00 \pm 8.61$ & 20 & $5.84 \pm 0.15^{* * *}$ & $1,067.30 \pm 84.55^{* * *}$ \\
\hline 45 & $7.45 \pm 0.36$ & $163.50 \pm 7.69$ & 30 & $4.91 \pm 0.36^{* *}$ & $1,941.00 \pm 275.50^{* * *}$ \\
\hline
\end{tabular}

** $P<0.01$ vs corresponding passive diffusion controls

*** $P<0.001$ vs corresponding passive diffusion controls

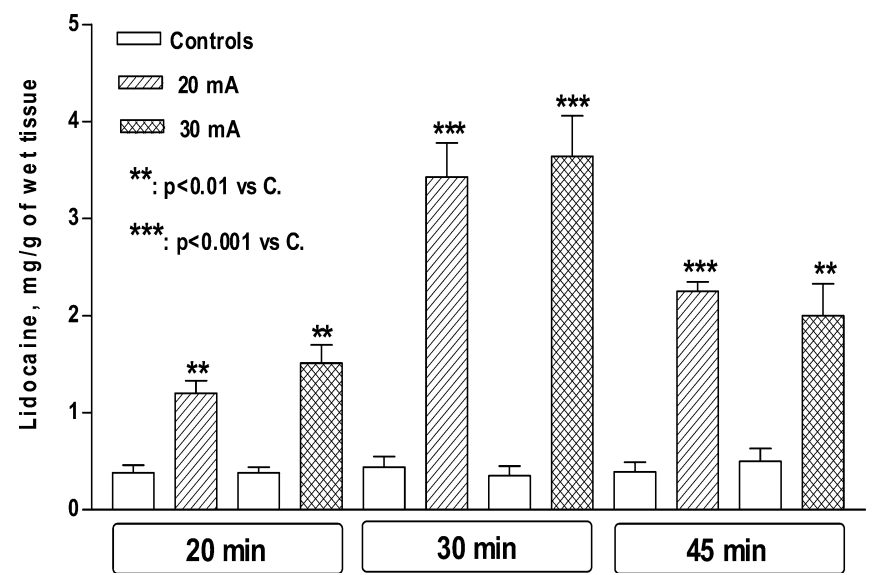

Fig. 3 Both $20 \mathrm{~mA}$ and $30 \mathrm{~mA}$ significantly increase the levels of lidocaine in vesical tissues with respect to controls at each time point tested. Data are expressed as $\mathrm{mg} / \mathrm{g}$ wet tissue, the means \pm SEM of four replicates per group are given. ${ }^{* *} P<0.01$ and $* * *, P<0.001$ versus the relevant controls (passive diffusion)

associated with measurement. This is intriguing, as both lidocaine and epinephrine have similar molecular weights (234 Da and $183 \mathrm{Da}$, respectively), they share certain chemical characteristics - a hydrophobic aromatic residue and a hydrophilic amine group - and both were in ionized form.

With the application of an electric current, lidocaine again demonstrated aberrant behaviour. Other ions in solution offered negligible competition and quantities of

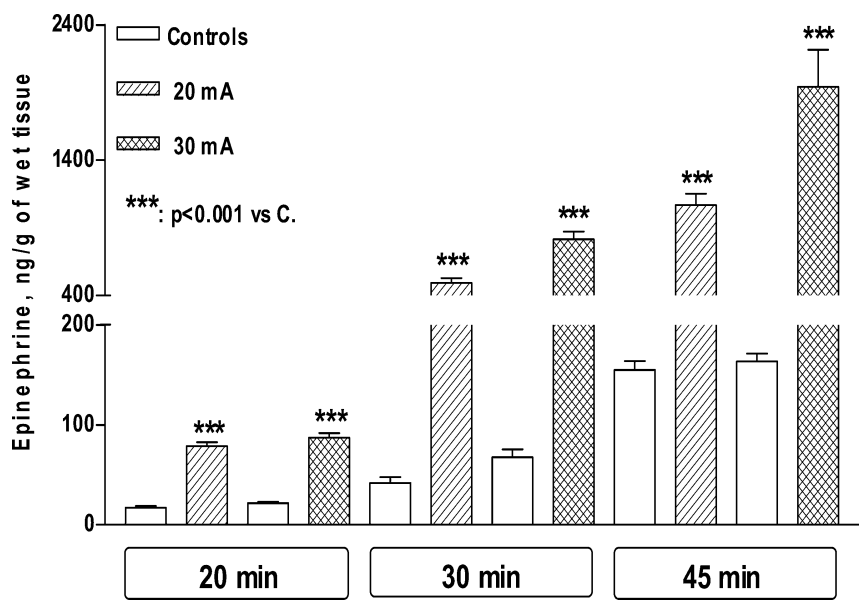

Fig. 4 Both $20 \mathrm{~mA}$ and $30 \mathrm{~mA}$ induce a significant increase in epinephrine levels in vesical tissues compared to controls at each time point tested. Data are expressed as $\mathrm{ng} / \mathrm{g}$ of wet tissue, the means \pm SEM of four replicates per group are given. $* * * P<0.001$ versus the relevant controls (passive diffusion)

lidocaine transported from time zero through 20 and $30 \mathrm{~min}$ appeared to increase linearly in accordance with simple electrochemistry (Appendix). But the amount of lidocaine transported at $45 \mathrm{~min}$ was less than that at $30 \mathrm{~min}$ at both $20 \mathrm{~mA}$ and $30 \mathrm{~mA}$, an aberration for which we have no explanation. Conversely, the very dilute epinephrine, totally outmatched by charge competition from all other ions in solution, demonstrated 


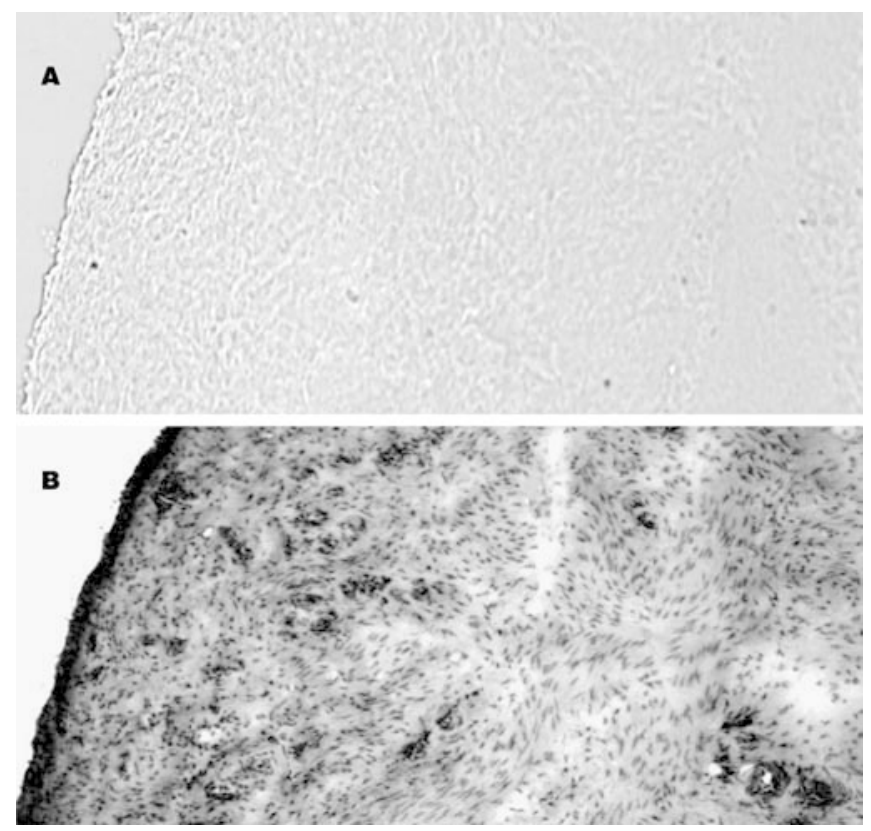

Fig. 5 Photomicrographs of pig bladder wall samples after the application of $30 \mathrm{~mA}$ - for $45 \mathrm{~min}$ : A Trypan blue exclusion test, and $\mathbf{B}$ stained with $\mathrm{H}$ and $\mathrm{E}$

the classical response of a quantitative linear increase from 20 through 45 min with a definite increase in slope for $30 \mathrm{~mA}$ as compared to $20 \mathrm{~mA}$. In turn, the values for both slopes exceeded those of the assumed slope from 0-20 min. Presumably, the bladder wall contains enzymes responsible for the metabolic transformation of epinephrine, especially catechol-0-methyltransferase (COMT). The small sections of bladder (average $2.5 \mathrm{~g}$ ) have a store of COMT which is not renewable and is exhausted by epinephrine concentrations of $75-150 \mathrm{ng} / \mathrm{g}$ wet tissue (Fig. 4), so after about 20 min epinephrine continues to accumulate in tissues without further transformation and measured quantities rise more steeply from $20-45 \mathrm{~min}$.

Finally, bladder wall is remarkably resilient when exposed to high current densities. In these present studies, maximum current densities were $30 \mathrm{~mA} /$ $1.8 \mathrm{~cm}^{2}=16.7 \mathrm{~mA} / \mathrm{cm}^{2}$ applied for $45 \mathrm{~min}$, and no tissue damage was detected histologically or by the trypan blue test. Conversely, the maximum recommended for human skin [1] is $0.5 \mathrm{~mA} / \mathrm{cm}^{2}$; current densities of $1.0 \mathrm{~mA} / \mathrm{cm}^{2}$ are distinctly uncomfortable and often result in small punctate burns; current densities $\geq 5 \mathrm{~mA} / \mathrm{cm}^{2}$ rapidly (5-10 $\mathrm{min}$ ) cause severe damage to the skin whether in vivo or in a laboratory cell. Almost certainly this difference is due to structural differences between the two tissues. Skin is inhomogeneous with numerous small perforations (hair follicles, sweat ducts) of lower electrical resistance tending to focus the current which causes burns. The bladder wall, especially the urothelium, is structurally homogeneous so that applied current is evenly dispersed over the whole exposed area. Nevertheless, the absence of microscopic tissue damage or death does not imply that there are no functional changes. Simple calculations reveal that the ratio of measured quantities $\left(\mathrm{M}_{\mathrm{L}}\right)$ of lidocaine transported (Table 1) to quantities $\left(\mathrm{T}_{\mathrm{L}}\right)$ calculated theoretically (Appendix), $\mathrm{M}_{\mathrm{L}}: \mathrm{T}_{\mathrm{L}}=2.3: 1$ (1.4:1-3.7:1) which indicates an increased permeability of the tissues under the influence of an electric current [12], thereby increasing the passive diffusion component.

In conclusion, lidocaine $\mathrm{HCl} 4 \%(\mathrm{NaCl}$-free) in $50 \mathrm{ml}$ vials, diluted with water to $2 \%$ and mixed on the day of use with epinephrine (final concentration 1/100,000) provides an electrochemically favorable, inexpensive, local anesthetic solution for intravesical electromotive administration. Electric currents of 20 and $30 \mathrm{~mA}$ increased administration rates of both lidocaine and epinephrine by factors of 6:1-13:1 and 9:1 respectively as compared to administration rates with passive diffusion. These quantitative studies provide pharmacologic, in vitro support for the results reported in clinical studies using electromotive administration of this drug combination. Just as importantly, the studies of epinephrine stability define a time limit of 1 day between mixing and application of the drug combination; failure to observe this limit will lead to suboptimal clinical results.

Acknowledgements Supported by grant "Progetti di Ricerca di Ateneo ex 60\% 2001-2002" from Tor Vergata University of Rome. Physion Srl (Medolla, MO, Italy) donated the electromotive equipment for the studies.

\section{References}

1. Banga AK, Chien YW (1988) Iontophoretic delivery of drugs: fundamentals, developments and biomedical applications. J Contr Release 7: 1

2. Di Stasi SM, Giannantoni A, Massoud R, Cortese C, Vespasiani G, Micali F (1997) Electromotive administration of oxybutynin into the human bladder wall. J Urol 158: 228

3. Di Stasi SM, Giannantoni A, Massoud R, Dolci S, Navarra P, Vespasiani G, Stephen RL (1999) Electromotive versus passive diffusion of mitomycin $\mathrm{C}$ into human bladder wall: concentration-depth profiles studies. Cancer Res 59: 4912

4. Fontanella UA, Rossi CA, Stephen RL (1997) Bladder and urethral anaesthesia with electromotive drug administration (EMDA): a technique for invasive endoscopic procedures. $\mathrm{Br} \mathbf{J}$ Urol 79: 414

5. Gürpinar T, Wong HY, Griffith DP (1996) Electromotive administration of intravesical lidocaine in patients with interstitial cystitis. J Endourol 10: 443

6. Henry R, Patterson L, Avery N, Tanzola R, Tod D, Hunter D, Nickel JC, Morales A (2001) Absorption of alkalized intravesical lidocaine in normal and inflamed bladders: a simple method for improving bladder anesthesia. J Urol 165: 1900

7. Hicks RM, Kettener B, Warren RC (1974) The ultrastructure and chemistry of the luminal plasma membrane of the mammalian urinary bladder: a structure with low permeability to water and ions. Phil Trans R Soc Lond B Biol Sci 268: 23

8. Jewett MAS, Valiquette L, Sampson HA, Katz J, Fradet Y, Redelmeier DA (1999) Electromotive drug administration of lidocaine as an alternative anesthesia for transurethral surgery. J Urol 161: 482

9. Lugnani F, Mazza G, Cerulli N, Rossi C, Stephen R (1993) Iontophoresis of drugs in the bladder wall: equipment and preliminary studies. Artif Organs 17: 8

10. Phipps JB, Padmanbhan RV, Lattin GA (1989) Iontophoretic delivery of model inorganic and drug ions. J Pharm Sci 78: 365 
11. Pode D, Zylber-Katz E, Shapiro A (1992) Intravesical lidocaine: topical anesthesia for bladder mucosal biopsies. J Urol 148: 795

12. Prausnitz MR, Bose VG, Langer R, Weaver JC (1993) Electroporation of mammalian skin: a mechanism to enhance transdermal drug delivery. Proc Nat Acad Sci U S A 90: 10504

13. Riedl CR, Knoll M, Plas E, Pfluger H (1998) Electromotive drug administration and hydrodistension for the treatment of interstitial cystitis. J Endourol 12: 269

\section{Appendix}

The following table describes the iontophoresis of lidocaine hydrochloride.
14. Ritchie JM, Greene NM (1990) Local anesthetics. In: Gilman AG, Rall TW, Nies AS (eds) The pharmacological basis of therapeutics. Pergamon Press, New York, p 311

15. Seeman P (1972) The membrane action of anesthetics and tranquilizers. Pharmacol Rev 24: 583

16. Thrasher JB, Kreder KJ, Peterson NE, Donatucci CF (1993) Lidocaine as topical anesthesia for bladder mappings and coldcup biopsies. J Urol 150: 335

Note: Eq. 5 in the table above states that significant quantities of small, highly mobile ions $\left(\mathrm{H}^{+}, \mathrm{Na}^{+}, \mathrm{Cl}^{-}\right)$ in the drug solution will cause a precipitous decline in $\mathrm{dL} / \mathrm{dt}$.
$J i(\mathrm{~mol} / \mathrm{sec})=\frac{I}{|z| \cdot F}$

$J i(\mathrm{mmol} / \mathrm{min})=I(6.2) \times 10^{-4} / z$

$J i(\mathrm{mg} / \mathrm{mA} \cdot \min )=M \cdot 6.2 \times 10^{-1} / z$

For any solution of lidocaine hydrochloride $\left(\mathrm{L}^{+}, \mathrm{Cl}^{-}\right)$:

$d L / d t(\mathrm{mg} / \mathrm{mA} \cdot \min )=235\left(6.2 \times 10^{-1}\right) \cdot t r_{L}$

$\operatorname{tr}_{L}=\frac{C_{L} \cdot \mu_{L} \cdot z_{L}}{\sum_{i=0}^{n}\left(C_{i} \cdot \mu_{i} \cdot z_{i}\right)}$

For a pure solution of lidocaine hydrochloride:

$\operatorname{tr}_{L}=\frac{C_{L} \cdot \mu_{L} \cdot z_{L}}{\left(C_{C l} \cdot \mu_{C l} z_{C l}\right)+\left(C_{L} \cdot \mu_{L} \cdot z_{L}\right)}$

And as $\mathrm{C}_{\mathrm{Cl}} \cdot \mathrm{z}_{\mathrm{Cl}}=\mathrm{C}_{\mathrm{L}} \cdot \mathrm{z}_{\mathrm{L}}$ (charge neutrality):

$\operatorname{tr}_{L}=\frac{1}{\underline{\mu_{C l}}+1}$

$d L / d t \stackrel{\frac{\mu_{C l}}{\mu_{L}}+1}{=} 235\left(6.2 \times 10^{-1}\right)\left(\frac{1}{\frac{\mu_{C l}}{\mu_{L}}+1}\right) \mu \mathrm{g} / \mathrm{mA} \cdot \min$
$\mu_{C l} / \mu_{L}=2 / 1$

$d L / d t=48.7 \mu \mathrm{g} / \mathrm{mA} \cdot \min$
(1) Ji is the flux of all ions; I is current in amperes; $|z|$ is absolute valency; $\mathrm{F}=96,486 \mathrm{C} / \mathrm{mol}$ (Faraday's Constant)

(2) $\mathrm{I}$ is current in $\mathrm{mA}$

(3) $\mathrm{M}$ is molecular weight (Da)

(4) $\operatorname{tr}_{\mathrm{L}}$ is the transference \# lidocaine. ( $\mathrm{z}=$ unity)

(5) $\mathrm{C}$ is concentration; $\mu$ is mobility; $\mathrm{i}$ is the summation index of all ions in solution
7)

(8)

(9) Estimated

(10) 